\title{
Announcements
}

\section{Charles E. Culpeper Foundation Scholarships in Medical Science}

The Charles E. Culpeper Foundation is currently accepting applications for its 1993 Scholarships in Medical Science Program designed to support the career development of academic physicians.

Up to three awards of $\$ 100,000$ per year for 3 years will be made to United States medical schools on behalf of candidates who are US citizens, who have received their MD degree from a US medical school in 1984 or later, and who are judged worthy of support by virtue of the quality of their research proposals. All scientific research relevant to human health is eligible for consideration. No institution may nominate more than one candidate.

In selecting awardees, emphasis will be on identifying young physicians with clear

potential for making substantial contributions to science as academic physicians. Since January 1988, 15 physicians have been selected as Charles E. Culpeper Foundation Medical Scholars, 3 each in the years 1988 through 1992.

Deadline for applications is August 14,

$\begin{array}{cclll}\text { 1992. Awards will be bynounced } & \text { be }\end{array}$ 15,1993 , for activation on or about July 1 , 1993. Application

forms $\quad$ and instructions may be obtained by contacting the Charles E. Culpeper Foundation Financial Centre 695 East Main Street, Suite 404 Stamford, CT 06901 (USA).

\section{International Symposium on the Pineal Gland: Its Molecular Signals}

Banaras, India December 14-15, 1992

The opportunity to review and update all aspects of the molecular signals transmitted by the pineal gland and to discuss their relevance in clinical understanding will be provided. The meeting will include a series of state-of-the-art lectures, selected short cummunications, and posters. The deadline

for submission of abstracts is September 30, 1992. Further information can be obtained from Prof. D. Gupta

Department of

Diagnostic Endocrinology

University Children's Hospital

D-W-7400 Tubingen (FRG).

\section{Drug Transport to the Brain: Concepts and Strategies}

October 9-11, 1992, Noordwijkerhout, The Netherlands

This symposium will be organized by the Center for Bio-Pharmaceutical Sciences. It is a post-congress event of the First European Congress of Pharmaceutical Sciences to be held in Amsterdam, October 7-9, 1992. For further information please contact the Symposium Secretariat:

Center for Bio-Pharmaceutical Sciences

PO Box 9502

NL-2300 RA Leiden (The Netherlands)

Tel.: 31-71274341

Telefax: 31-71274277

\section{1th Joint Meeting of the British Endocrine Societies}

Liverpool, UK

March 29.-April 1, 1993

The Programme Organizing Committee chairman is Prof. M. C. Sheppard from Birmingham and the Local Organizing Committee is chaired by Dr. M. C. White from Liverpool. Symposia: Endocrine Autoimmunity (jointly with the British Diabetic 
Association); Aetiology of Endocrine Tumours; Paracrinology of Early Pregnancy; Angiogenesis as an Endocrine Response; Steroids and the Brain; Clinical aspects of the Renin-Angiotensin-Aldo-sterone Axis. Clinical Management Workshops : Secondary Osteoporosis; Endocrine Management of Breast Cancer; Manage-

ment of Thyroid Eye Disease. The meeting will also feature Plenary Lectures, Methods Updates, Oral Communications and Poster Sessions, together with a Commercial Exhibition.

Further details available from

Janet Crompton

Administrative Officer

British Endocrine Societies

17/18 North Court

The Courtyard, Woodlands

Almondsbury, Bristol BS 12 4NQ (UK)

Tel.: (0)454 616046

Fax: (0)454 616071 